\title{
Effects of 24-hours/day versus business hours physical therapy intervention in adult intensive care unit patients: a systematic review
}

\begin{abstract}
Background: Some evidence suggests that higher doses of mobilization could have benefits on functional status. However, the impact of increasing the availability of Physical Therapist in the intensive care unit to provide critical care for these conditions is unclear

Objective: to determine the effect of physical therapy 24-hour/7days on the length of stay, index of respiratory system infection, days of mechanical ventilation, mortality and quality of life, in adult patients admitted to an intensive care unit.

Methods and design: The databases EMBASE, MEDLINE, PUBMED, and reference lists of previous reviews were searched for clinical trials and observational studies, without restriction on language or publication date. Four reviewers independently screened articles for eligibility, and included studies were appraised using the ROBINS-I risk of bias tool for non-randomised studies.

Results: 4509 records were screened. Two prospective cohorts were included in the review. Both studies reported significant improvements in length of intensive care unit stay and days of mechanical ventilation, while the index of respiratory system infection and mortality had unclear improvement. No studies reported quality of life in patients.

Conclusion: There was insufficient robust data to conclude that increasing availability of physical therapy beyond business hours could shorten the length of ICU stay and days of mechanical ventilation. Further studies are required to increase certainty about the effectiveness of Physical Therapist intervention 24-hours/7 days in intensive care unit.
\end{abstract}

Keywords: physical therapy, intensive care units, after-hours care, rehabilitation, review, length of stay, mechanical ventilation
Volume 3 Issue I - 2018

\author{
Catalina Merino-Osorio,' Ana Cristina \\ Castro-Ávila, ',2 Ruvistay Gutiérrez- \\ Arias, ${ }^{3}$ María Jesús Arriagada,' Catalina \\ Villanueva,' Jaime Leppe,' Carolina Fu ${ }^{4}$ \\ 'Facultad de Medicina Clínica Alemana Universidad del \\ Desarrollo, Chile \\ ${ }^{2}$ Department of Health Sciences, University of York, United \\ Kingdom \\ ${ }^{3}$ Instituto Nacional del Tórax, Chile \\ ${ }^{4}$ Departamento de Fisioterapia, Fonoaudiologia e Terapia \\ Ocupacional, Faculdade de Medicina-Universidade São Paulo, \\ Brazil.
}

Correspondence: Catalina Merino-Osorio, Carrera de Kinesiología, Facultad de Medicina Clínica Alemana Universidad del Desarrollo, Av. Plaza 680, Las Condes, Santiago, Chile, Tel +56223279269, Email catalinamerino@udd.cl

Received: January 02, 2018 | Published: February 27, 2018
Abbreviations: ESICM, european society of intensive care medicine; ICU, intensive care unit; OR, odds ratio; PT, physical therapist

\section{Introduction}

The intensive care unit (ICU) is a distinct organizational and geographic entity for clinical activity and care, operating in cooperation with other departments integrated into a hospital. ${ }^{1}$ The objectives of an ICU are the monitoring and support of threatened or failing vital functions in critically ill patients who have a condition with the potential to endanger life. ${ }^{1}$

Despite the evolution of intensive care medicine, there are frequent physical and psychological sequelae associated with ICU stay that remain at hospital discharge. ${ }^{2,3}$ Physical therapy intervention in ICU improves quality of life, physical function, ${ }^{4}$ and muscle strength; ${ }^{5}$ and decreases days of mechanical ventilation, length of stay in ICU, ${ }^{5-7}$ and mortality (6) of patients in these units. Therapeutic interventions in ventilated and non-mechanically ventilated patients contributing to this effect are: mucus clearance techniques, increased inspiratory volumes, active-assisted or active exercise, sitting in bed, sitting over the edge of the bed, stepping in place, walking in the corridor, transferring from bed or chair, and standing in tilt-table. ${ }^{5-8}$ Some of these techniques used as early rehabilitation during ICU stay seem to improve walking ability without assistance at hospital discharge. ${ }^{9}$ The new evidence suggests beneficial effects of mobilization on outcomes such as the ICU and hospital length of stay that confirms an unquestionable role for physiotherapy in the ICU. ${ }^{7}$

The European Society of Intensive Care Medicine (ESICM) recommends the presence of one Physical Therapist (PT) per five beds in a level III ICU. PTs should have specialized training and experience in critically ill patients and be available 7 days/week. ${ }^{1}$ Recent studies show that additional after-hours rehabilitation can increase physical activity and may improve activities of daily living of adult inpatients in a subacute or rehabilitation setting. ${ }^{10}$ Nevertheless, a study conducted in 460 ICUs from 17 countries of Europe, showed that only $35 \%$ of services have PTs working 24 hours per day. ${ }^{11}$ In Australia, less than $10 \%$ of the ICUs had weekday or weekend evening physiotherapy coverage. ${ }^{12}$

The impact on the length of wait and length of stay reduction were performed in physiotherapy services in Australian hospital emergency departments organized in shifts. ${ }^{13}$ Considering the potential benefits of physical therapy reported by the literature, it is expected that the effect of the physical therapy in clinical outcomes will be dosedependent. However, the effect of physical therapy 24 hours versus business hours only of adult patients in ICU is unknown. 
The aim of this systematic review is to determine the effect of physical therapy 24-hour/7days on the length of stay, index of respiratory system infection, days of mechanical ventilation, mortality and quality of life, in adult patients admitted to an ICU.

\section{Methods/design}

\section{Data sources and selection criteria}

A systematic search was conducted in EMBASE (1974 to 2016 November $\left.29^{\text {th }}\right)$, MEDLINE (1946 to 2016 November $29^{\text {th }}$ ) and PUBMED databases, and reference lists of previous reviews were screened for relevant studies, without restriction on language or publication date. Last electronic search was conducted on November $30^{\text {th }}$ 2016, combining free words and indexed terms concerning physical therapy, 24-hour working schemes, and intensive care unit, adapting the strategy to each of the databases. See the Supplementary Material 1 for keywords used to find the articles for this review and the full search strategy.

Four reviewers screened titles and abstracts to identify relevant studies against eligibility criteria established a priori. In case of disagreements, reviewers discussed until reaching consensus; and if differences persisted, an external reviewer mediated until disagreements were resolved. Where necessary, authors of articles screened were contacted to provide additional data to allow their inclusion in the review. The criteria for inclusion of studies in the review are presented in Figure 1.

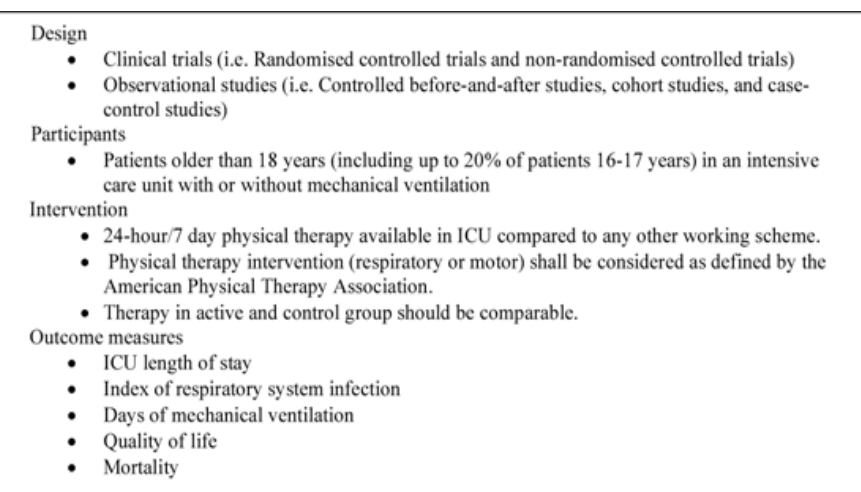

Figure I Inclusion criteria.

\section{Quality assessment of articles and data extraction}

Three authors independently examined the full-text version of studies reports included in the review to extract data and assess the risk of bias, using the ROBINS-I assessment tool for non-randomised studies. ${ }^{14}$

The data extraction form was piloted by three reviewers with one study classified as eligible and modified to facilitate extraction. Three reviewers independently extracted information regarding methods and results, which were checked by a third reviewer.

To describe the information collected from each article, the study design, sample size, characteristics of the population under study (age, gender, and admission diagnosis), intervention characteristics, primary and secondary outcomes, and the results obtained for each outcome were recorded.

\section{Participants}

Participants in the included studies must be older than 18 years (including up to $20 \%$ of patients $16-17$ years), receiving care in an intensive care unit with or without mechanical ventilation.

\section{Interventions}

The experimental intervention (24-hour/7 days Physical Therapy Group) was physical therapy intervention (respiratory or motor) provided by a PT according to the definition of the American Physical Therapy Association.The control intervention (Business hours Physical Therapy Group) must be an equivalent intervention to that of the active group but provided for fewer than 168 hours/week.

\section{Types of outcomes}

\section{i. Primary outcome}

Length of stay on ICU was measured in days.

\section{ii. Secondary outcome}

Index of respiratory system infection was calculated by the number of patients who presented respiratory infection after the admission to the ICU, divided by the total number of admitted patients. Days of mechanical ventilation was measured in days from the moment of tracheal intubation to the moment of extubation.

Quality of life was measured using all types of questionnaires included in the reviewed articles (e.g., health-related quality of life HRQOL, International Quality of Life Assessment IQOLA). Mortality was measured by the number of deaths occurred within the ICU hospitalization period.

\section{Data analysis}

A descriptive analysis of data collected for each of the items and a structured synthesis are presented. Tables were made for study design characteristics, demographic characteristics of participants, description of interventions, and the assessment of the risk of bias. Subgroup analyses per study design, admission diagnosis (i.e. neurosurgical pathologies, cardio-respiratory, trauma and medical diseases) and the number of sessions were initially planned, but due to limited data, these were not performed.

The protocol for this systematic review was registered $a$ priori in PROSPERO (CRD42016038256) and this article follows the PRISMA reporting guideline for systematic reviews (Supplementary Material 2).

\section{Results}

\section{Flow of trials through the review}

The electronic search strategy identified 4509 papers, of which 336 were duplicates, and eight were retrieved in full text and screened for eligibility (Figure 2). 4165 studies were excluded after revision of titles and abstracts for failing to meet more than one inclusion criteria. A systematic review ${ }^{15}$ of additional physiotherapy to hospital inpatients outside of regular business hours was identified by the search. Screening of the reference list identified one article potentially eligible ${ }^{16}$ but it was excluded because intervention started out of the 
ICU. No clinical trials were found, and two observational studies met the inclusion criteria, which were included in the review. One of them was grey literature (i.e. MSc dissertation); therefore, it was necessary to ask the authors for access to the full-text document.

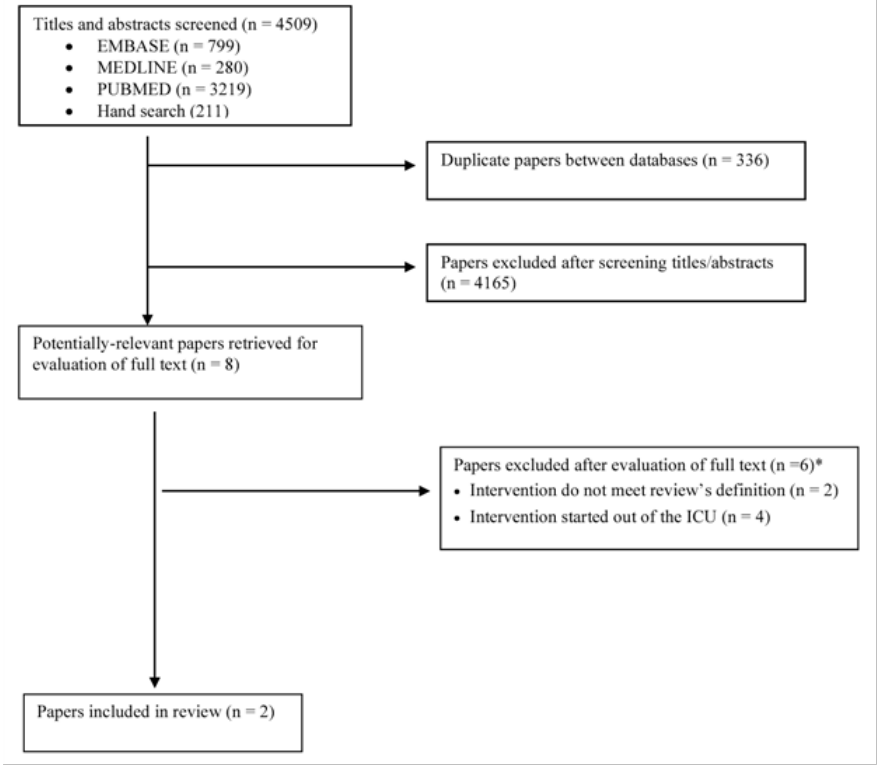

Figure 2 Flow of studies through the review.

*Papers may have been excluded for failing to meet more than one inclusion criteria.

Table I Description of design, population, clinical setting, details about intervention and control group and outcomes measures of included studies in the systematic review.

\begin{tabular}{|c|c|c|c|c|c|c|}
\hline \multirow{2}{*}{ Study } & \multirow{2}{*}{ Design } & \multirow{2}{*}{ Population } & \multirow{2}{*}{ Clinical setting } & \multicolumn{2}{|c|}{ Description } & \multirow{2}{*}{$\begin{array}{l}\text { Outcome } \\
\text { measures }\end{array}$} \\
\hline & & & & Intervention & Control & \\
\hline $\begin{array}{l}\text { Castro } \\
\text { et al. }{ }^{6}\end{array}$ & $\begin{array}{c}\text { Prospective } \\
\text { Cohort }\end{array}$ & $\begin{array}{l}\text { Patients admitted into } \\
\text { the general ICU and } \\
\text { patients eligible to } \\
\text { physical therapy after } \\
\text { the initial assessment } \\
\text { of the referring doctor } \\
\text { and the unit physical } \\
\text { therapist. }\end{array}$ & $\begin{array}{l}\text { ICUs of two } \\
\text { public hospitals } \\
\text { with a different } \\
\text { number of } \\
\text { physiotherapists } \\
\text { hired in São } \\
\text { Paulo, Brazil. }\end{array}$ & $\begin{array}{l}\text { Chest Physical therapy: } \\
\text { mucus removal techniques } \\
\text { (endotracheal suctioning } \\
\text { and manual thorax } \\
\text { percussion) } \\
\text { General mobilization: upper } \\
\text { and lower limbs } \\
\text { Dose: } 24 \text { hours/day, for at } \\
\text { least } 4 \text { times. }\end{array}$ & $\begin{array}{l}\text { Chest Physical therapy and } \\
\text { general mobilization. } \\
\text { Dose: } 6 \text { hours/day, one visit } \\
\text { regardless need. }\end{array}$ & $\begin{array}{l}\text { - ICU length of } \\
\text { stay } \\
\text { - Length of stay } \\
\text { in mechanical } \\
\text { ventilation } \\
\text { - Incidence of } \\
\text { pulmonary } \\
\text { infections } \\
\text { - Mortality }\end{array}$ \\
\hline $\begin{array}{c}\text { Da } \\
\text { Silva et } \\
\text { al. }^{17}\end{array}$ & $\begin{array}{c}\text { Prospective } \\
\text { Cohort }\end{array}$ & $\begin{array}{l}\text { Patients admitted } \\
\text { into ICU for routine } \\
\text { postoperative } \\
\text { treatment and } \\
\text { underwent IMV } \geq 24 \\
\text { hours. }\end{array}$ & $\begin{array}{l}\text { I I Surgical ICUs } \\
\text { of Hospital das } \\
\text { Clínicas, São } \\
\text { Paulo, Brazil; } \\
\text { three with } \\
\text { physical therapist } \\
24 \text { hour/day } \\
\text { and eight with } \\
\text { physical therapist } \\
\text { available I } 2 \text { hour/ } \\
\text { day. }\end{array}$ & $\begin{array}{l}\text { Routine daily physical } \\
\text { therapy, without specific } \\
\text { intervention protocol. } \\
\text { Dose: } 24 \text { hours/day, median } \\
\text { of } 25 \text { chest physical therapy } \\
\text { and I } 5 \text { motor physical } \\
\text { therapy sessions according } \\
\text { to patient need. }\end{array}$ & $\begin{array}{l}\text { Routine daily physical therapy, } \\
\text { without specific intervention } \\
\text { protocol. Dose: I } 2 \text { hours/day, } \\
\text { median of } 20 \text { chest physical } \\
\text { therapy and I } 4 \text { motor physical } \\
\text { therapy sessions according to } \\
\text { patient need. }\end{array}$ & $\begin{array}{l}\text { - Length of IMV } \\
\text { - ICU length of } \\
\text { stay } \\
\text { - Frequency of } \\
\text { respiratory } \\
\text { complications } \\
\text { related to IMV } \\
\text { - Mortality } \\
\text { - Indirect } \\
\text { costs of } \\
\text { postoperative } \\
\text { patients }\end{array}$ \\
\hline
\end{tabular}

ICU, intensive care unit; IMV, invasive mechanical ventilation

\section{Characteristics of the included studies}

Two prospective cohorts investigated a total of 412 participants of medical and surgical ICUs from São Paulo, Brazil. Two hundred and twenty-five $(54.6 \%)$ belonged to the intervention groups and 187 $(45.4 \%)$ to the control group. One hundred fifty $(36.4 \%)$ were females, and the APACHE II score did not show statistically significant differences between the intervention and control groups in each study. Description of design, population, clinical setting, details about intervention and control group and outcomes measured of included studies are shown in Table 1, and demographic characteristics of patients included are available in Table 2.

Regarding the characteristics of the intervention, Castro et al. ${ }^{6}$ reported a mean of 52.8 hours of overall time of chest physical therapy in the 24-hour/7 days physical therapy group, compared to 25 overall number of chest physical therapy reported by Da Silva et al. ${ }^{17}$ (Table $3)$. The information available in the articles is not enough to identify the intervention time per patient.

\section{Study quality assessment}

The studies included in the review were judged as having a serious overall risk of bias, mainly by bias due to confounding and selection of participants. Details about methodological quality assessment based on ROBINS-I assessment tool ${ }^{14}$ can be found in Table 4 . 


\section{Main results}

i. Effect of physical therapy 24-hours/7 days on length of stay on ICU

Both studies included in this review found significant reduction in length of ICU stay (p-value $=0.003$ and 0.015 for Castro et al. ${ }^{6}$ and Da
Silva et al. ${ }^{17}$ respectively), with at least five days less in intervention group (Table 3 )
ii. Effect of physical therapy 24-hours/7 days on index of respiratory system infection, days of mechanical ventilation, and mortality

Table 2 Demographic characteristics of patients included studies in the systematic review.

\begin{tabular}{ccccccc}
\hline Study & Group & $\begin{array}{c}\text { Sample } \\
\text { Size }(\mathbf{n})\end{array}$ & Age, years & $\begin{array}{c}\text { Gender, } \\
\text { females }\end{array}$ & $\begin{array}{c}\text { \$APACHE II } \\
\text { score }\end{array}$ & Admission diagnosis* \\
\hline $\begin{array}{c}\text { Castro et } \\
\text { al. }{ }^{6}\end{array}$ & Intervention & 73 & $54.51 \pm 18.4$ & $27(37)$ & $19.90 \pm 12.2$ & Systemic arterial hypertension, 20 (20.4) \\
& Control & 73 & $50.25 \pm 18.9$ & $25(34)$ & $20.40 \pm 7.7$ & Brain trauma, 24 (19.6) \\
$\begin{array}{c}\text { Da Silva et } \\
\text { al. }{ }^{17}\end{array}$ & Intervention & 152 & $59(50-67)$ & $62(4 I)$ & $13(9-17)$ & Abdominal surgery, 44 (29) \\
& Control & 114 & $51(38-64)$ & $36(32)$ & $12(9-17)$ & Neurosurgery, 6I (53)
\end{tabular}

Values reported in $\mathrm{n}(\%)$, mean \pm Standard Deviation or $\mathrm{P}_{50}\left(\mathrm{P}_{25}-\mathrm{P}_{75}\right)$.

$\S$ APACHE II score:Acute physiological and chronic health evaluation II scores. It measures severity of disease. It is assessed within 24 hours since admission to intensive care. Scores range from 0 to $7 \mathrm{I}$ and are associated with predicted mortality. 25-29 points have predicted mortality of 55\% for non-operative admission and $35 \%$ post-surgery; $\geq 35$ points have $85 \%$, and $88 \%$ predicted mortality for non-surgical and post-surgical admission, respectively( 28 ). No statistically significant differences between the intervention and control groups in each study.

*Only most prevalent admission diagnoses for every study are reported in this table.

Table 3 Description duration of therapy, ICU length of stay, index of respiratory infection, days of mechanical ventilation, quality of life and mortality of intervention and control group of included studies in the systematic review.

\begin{tabular}{|c|c|c|c|c|c|c|c|c|}
\hline Study & Group & $\begin{array}{c}\text { Duration } \\
\text { of therapy, } \\
\text { hours }\end{array}$ & $\begin{array}{c}\text { Number of } \\
\text { sessions }\end{array}$ & $\begin{array}{l}\text { Length of } \\
\text { stay in ICU, } \\
\text { days }\end{array}$ & $\begin{array}{l}\text { Index of } \\
\text { respiratory } \\
\text { system } \\
\text { infection }\end{array}$ & $\begin{array}{c}\text { Days of } \\
\text { mechanical } \\
\text { ventilation }\end{array}$ & $\begin{array}{l}\text { Quality } \\
\text { of life }\end{array}$ & Mortality \\
\hline \multirow[b]{2}{*}{ Castro et al. ${ }^{6}$} & Intervention & $52.8 \pm 2^{\S}$ & $N / R$ & $13.2 \pm 12.6^{\circ}$ & $0.356^{\varnothing}$ & $10 \pm 20^{\circ}$ & $N / R$ & $20(27.3)^{\varnothing}$ \\
\hline & Control & $21.6 \pm 1.5^{\S}$ & $N / R$ & $21.6 \pm 17.8^{\varnothing}$ & $0.616^{\circ}$ & $15 \pm 12^{\varnothing}$ & $N / R$ & $26(35.5)^{\varnothing}$ \\
\hline \multirow{2}{*}{$\begin{array}{c}\text { Da Silva et } \\
\text { al. }^{17}\end{array}$} & Intervention & $N / R$ & $\begin{array}{c}25(13-44)^{*} \\
15(8-27)^{\diamond}\end{array}$ & $10(-)^{\varnothing}$ & 0.243 & $4^{\varnothing}$ & $N / R$ & $7(5)^{\dagger}$ \\
\hline & Control & $N / R$ & $\begin{array}{c}20(10-36)^{*} \\
14(5-26)^{\circ}\end{array}$ & $15(-)^{\varnothing}$ & 0.210 & $6^{\circ}$ & $N / R$ & $5(4)^{\dagger}$ \\
\hline
\end{tabular}

Values reported in $\mathrm{n}(\%)$, mean \pm Standard Deviation or $\mathrm{P}_{50}\left(\mathrm{P}_{25}-\mathrm{P}_{75}\right)$.

ICU, intensive care unit, N/R, not reported.

§reported overall time of chest physical therapy in hours; $p=0.00 \mathrm{I}$

*reported overall number of chest physical therapy; $\mathrm{p}=0.014$

৩reported overall number of physical therapy, $p=0.284$

$\varnothing$ statistically significant difference; $p<0.05$

treported mortality at day 28 of study entry.

The intervention group in Castro et al. study had a lower index of respiratory system infection ( $\mathrm{p}$-value $=0.0043$ ) and mortality $(\mathrm{OR}$ $1.3,95 \%$ IC 1.08-2-33, $\mathrm{p}=0.04$ for control group). ${ }^{6} \mathrm{Da}$ Silva ${ }^{17} \mathrm{did}$ not found a significant difference in these outcomes ( $\mathrm{p}$-value $=0.704$ and $\mathrm{p}=1.00$ respectively).

Castro et al. ${ }^{6}$ reported longer mechanical ventilation length of

stay probability for the control group (OR 3.8, 95\% IC 1.65-9.12, $\mathrm{p}=0.0001$ ), while Da Silva(17) found the 24-hour/7 days physical therapy group had a lower median of days spent in mechanical ventilation (4 versus 6 days, p-value $=0.002)$ (Table 3$)$.

iii. Effect of physical therapy 24-hours/7 days on quality of life

No studies reported results for quality of life. 
Table 4 Quality assessment based on Cochrane Collaboration's Risk of Bias tool of included studies in the systematic review.

\begin{tabular}{|c|c|c|c|c|c|c|c|c|}
\hline $\begin{array}{l}\text { Component } \\
\text { study }\end{array}$ & domain & & & & & & & $\begin{array}{c}\text { Overall RoB } \\
\text { judgment }\end{array}$ \\
\hline $\begin{array}{c}\text { Cohort study } \\
\text { design }\end{array}$ & $\begin{array}{l}\text { Bias due to } \\
\text { confounding }\end{array}$ & $\begin{array}{l}\text { Bias in } \\
\text { selection of } \\
\text { participants }\end{array}$ & $\begin{array}{l}\text { Bias in } \\
\text { measurement of } \\
\text { interventions }\end{array}$ & $\begin{array}{l}\text { Bias due to } \\
\text { departures } \\
\text { from intended } \\
\text { interventions }\end{array}$ & $\begin{array}{l}\text { Bias due to } \\
\text { missing data }\end{array}$ & $\begin{array}{l}\text { Bias in } \\
\text { measurement } \\
\text { of outcomes }\end{array}$ & $\begin{array}{l}\text { Bias in } \\
\text { selection of } \\
\text { reported } \\
\text { results }\end{array}$ & \\
\hline $\begin{array}{l}\text { Castro et al. } \\
(2013)\end{array}$ & Serious & Moderate & Moderate & Low & Low & Moderate & Serious & Serious \\
\hline $\begin{array}{l}\text { Da Silva et al. } \\
\qquad(20 \mid 2)\end{array}$ & Critical & Moderate & Moderate & Low & Moderate & Moderate & Moderate & Critical \\
\hline
\end{tabular}

RoB, risk of bias

\section{Discussion}

This review found low-quality evidence suggesting that physical therapy 24-hour/7 days reduces length of stay in ICU, days of mechanical ventilation, and inconsistent evidence that it improves the index of respiratory system infection and mortality. ${ }^{6,17}$ No studies were found reporting the effect on quality of life in adult patients in ICU for this comparison. The evidence indicates that no clinical trials have been conducted comparing the effect of physical therapy 24-hours/7 days versus business hours on ICU patients. Considering that the quality of the evidence included in this review comes from two observational studies with high risk of bias, the results should be taken with caution.

Evidence suggests that physical therapy for adult patients in ICU improves pulmonary and hemodynamic function, reducing pulmonary complications and the need for mechanical ventilation. $2,8,18,19$ Moreover, an overview of systematic reviews that synthesized the evidence of physical rehabilitation during critical illness suggest that there is currently no requirement for further systematic reviews on physical interventions delivered within the ICU, ${ }^{20}$ but the evidence of the effect of physical therapy activities available 24-hours/7 days compared with business hours in ICU is still limited.

The European Society of Intensive Care Medicine and some national critical care societies (e.g. Chilean Society, American College of Critical Care Medicine and Society of Critical Care Medicine) recommend that a PT or respiratory therapist should be available 24 hours a day in level III ICUs. ${ }^{1,21,22}$ Duncan et al. ${ }^{23}$ showed that an increase in weekend physiotherapy in the ICU generates a significant impact on the number of patients treated and the number of PT sessions conducted. Additionally, physiotherapists perceive having more possibilities to carry out specific treatments, whereas patient complications are decreased. ${ }^{23}$ Nevertheless, an integrative literature review reported that critically ill patients do not always receive PT interventions as a standard of care, and the availability of physical and occupational therapists represented a significant barrier to the delivery of therapy. ${ }^{24}$ This may limit the existence of studies attempting to determine the effect of PT interventions according to the PT's time availability.

The lack of studies comparing the effect of 24 hours versus business hours PT on quality of life of adult patients in ICU can be explained because few studies have explored the effect of physical therapy on quality of life of adult patients in UCI, and those that exist have not compared groups with different availability of physical therapy. ${ }^{25}$ Tipping et al. ${ }^{25}$ showed that high dose of rehabilitation in ICU patients -defined as daily active rehabilitation completing over 30 minutes- compared to those receiving less than 30 minutes daily, might lead to improved quality of life at six months in the physical and emotional role domain. ${ }^{25}$ The few studies included in this review also decrease the likelihood that some of them will report the effect of quality of life.

Despite the comprehensive search strategy used, we could not identify ongoing or completed clinical trials comparing the interventions of this review. This is similar to the findings of two other recent reviews that have confirmed the lack of studies comparing the effect of the PT intervention according to the hours PTs are available in the ICU. ${ }^{20,25}$ It was also reported that due to a lack of good quality randomized controlled trials and inconsistent outcome measurement, there is insufficient evidence to support beneficial effects of PT intervention delivered post-ICU discharge. ${ }^{20}$ Probably, the lack of standardization of the interventions ${ }^{8}$ as well as the dose in terms of intensity, duration and frequency ${ }^{7}$ are the main factors for not detecting an effect on these outcomes, and more studies are needed to particularly assess appropriate dosage and timing of therapy. ${ }^{4,25}$

Recent systematic reviews show that early active mobilization protocols may be initiated in the ICU setting ${ }^{26}$ and are an effective intervention that can have significant impact on functional outcomes. ${ }^{4,27}$ That is why further studies are necessary to standardize the intervention in adult ICU patients and compare the effect of physical therapy activities available 24-hours/7 days in clinical and functional outcomes. Additionally, determining the effect of physical therapy 24-hours/7 days versus business hours only in ICU patients would not only provide clinical information, but it would contribute with information about the most efficient PT staffing ratio in the ICU. ${ }^{28}$

\section{Study limitations}

This review has some limitations. First, variability in the protocol of interventions in the studies compared is a confounder that must be considered before generalizing findings of this review to other adult's critically ill patients. Future reviews should be more rigorous in 
terms of comparability of interventions regarding dose and activities performed during physical therapy sessions. Second, due to the selection of participants in the two studies included in this review, the control group had a higher proportion of diagnoses associated with greater severity and worse prognosis such as neurosurgical diseases Although the beneficial effect of physical therapy in the intervention group could be explained by the level of severity at admission, the APACHE II score did not significantly differ between the two groups. Third, the access to one article was limited by the availability of fulltext document, which is currently not available in scientific databases. For the inclusion in this review, the raw information was provided directly by the authors, lacking a peer review. Finally, the articles included in this review were only observational cohorts -without randomization- that produce an overestimation of the treatment effect; therefore, the overall effect reported should be interpreted carefully. Although we conducted a methodologically rigorous systematic review, the robustness of our conclusions has been limited by the number and quality of studies available.

\section{Conclusion}

In conclusion, there was insufficient robust data to conclude that increasing availability of physical therapy beyond business hours could shorten length of ICU stay and days of mechanical ventilation. There was no conclusive information regarding the effect on improving the index of respiratory system infection and mortality, and no studies reported the effect on quality of life. No clinical trials have been conducted comparing the effect of physical therapy 24-hours/7 days versus business hours only in ICU patients. Further studies are required to increase certainty about the effect of PT intervention 24-hours/7 days in ICU.

\section{Acknowledgements}

None.

\section{Conflict of interest}

The authors report no potential financial or ethical conflicts of interest regarding the contents of the submission. No funding sources were involved in this study.

\section{References}

1. Valentin A, Ferdinande P, ESICM, et al. Recommendations on basic requirements for intensive care units: structural and organizational aspects. Intensive Care Med. 2011;37:1575-87.

2. Herridge M, Cheung A. One-year outcomes in survivors of the acute respiratory distress syndrome. $N$ Engl J Med. 2003; 348(8):683-93.

3. Herridge M, Tansey C. Tomlinson G, et al. Functional disability 5 years after acute respiratory distress syndrome. N Engl J Med. 2011; 364(14):1293-304.

4. Calvo-Ayala E, Khan B, Farber M.et al. Interventions to Improve the Physical Function of ICU Survivors. Chest. 2013;144(5):1469-80.

5. Kayambu G, Boots R, Paratz J. Physical Therapy for the Critically Ill in the ICU: A Systematic Review and Meta-Analysis. Crit Care Med. 2013;41(6):1543-54

6. Castro AAM, Ramos S, Oliveira AB, et al. Chest physiotherapy effectiveness to reduce hospitalization and mechanical ventilation length of stay, pulmonary infection rate and mortality in ICU patients. Respir Med. 2013;107(1):68-74.
7. Stiller K.Physiotherapy in intensive care: An updated systematic review. Chest. 2013;144(3):825-47.

8. Gosselink R, Bott J, Johnson M, et al. Physiotherapy for adult patients with critical illness: Recommendations of the European Respiratory Society and European Society of Intensive Care Medicine Task Force on Physiotherapy for Critically Ill Patients. Intensive Care Med. 2008;34(7):1188-99.

9. Castro AAC, Serón P, Fan E, et al. Effect of early rehabilitation during intensive care unit stay on functional status: Systematic review and metaanalysis. PLoS One. 2015;10(7):1-21.

10. Scrivener K, Jones T, Schurr K, et al. After-hours or weekend rehabilitation improves outcomes and increases physical activity but does not affect length of stay: A systematic review. J Physiother. 2015;61(2):61-7.

11. Norrenberg M, Vincent JL. with the collaboration of the European Society of Intensive Care Medicine (2000) A profile of European intensive care unit physiotherapists. Intensive Care Med. 2000;26(7):988-94.

12. Chaboyer W, Gass E, Foster M. Patterns of chest physiotherapy in Australian Intensive Care Units. J Crit Care. 2004;19(3):145-51.

13. Morris J, Vine K, Grimmer K. Evaluation of performance quality of an advanced scope physiotherapy role in a hospital emergency department. Patient Relat Outcome Meas. 2015;6:191-203.

14. Sterne JA, Hernán MA, Reeves BC, et al. ROBINS-I: a tool for assessing risk of bias in non-randomised studies of interventions. BMJ. 2016;355:i4919.

15. Brusco NK, Paratz J. The effect of additional physiotherapy to hospital inpatients outside of regular business hours: a systematic review. Physiother Theory Pract. 2006;22(6):291-307.

16. Van PID, Vliet VTP, Versteegh MI, et al. Exercise therapy after coronary artery bypass graft surgery: a randomized comparison of a high and low frequency exercise therapy program. Ann Thorac Surg. 2004;77(5):153541.

17. Da Silva, Janete M. Impacto da assistência fisioterapêutica em unidade de terapia intensiva no tempo de ventilação mecânica, tempo de internação e custos do paciente cirúrgico [dissertação]. Faculdade de Medicina, Universidade de São Paulo; 2012.

18. Babu A, Noone M, Haneef M, et al. The effects of "on-call/out of hours" physical therapy in acute exacerbations of chronic obstructive pulmonary disease: a randomized controlled trial. Clin Rehabil. 2010;24(9):802809.

19. Schweickert WD, Pohlman MC, Pohlman AS, et al. Early physical and occupational therapy in mechanically ventilated, critically ill patients: a randomised controlled trial. Lancet. 2009;373(9678):1874-82.

20. Connolly B, O’Neill B, Salisbury L, et al. Physical rehabilitation interventions for adult patients during critical illness: An overview of systematic reviews. Thorax. 2016;71(10):881-90.

21. Haupt MT, Bekes CE, Brilli RJ, et al. Guidelines on critical care services and personnel: Recommendations based on a system of categorization of three levels of care. Crit Care Med. 2003;31(11):2677-83.

22. Saez E. Guías 2004 de organización y funcionamiento de unidades de pacientes críticos. Rev Chil Med Intensiva. 2004; 19(4):209-23.

23. Duncan C, Hudson M, Heck C. The impact of increased weekend physiotherapy service provision in critical care: a mixed methods study. Physiother Theory Pract. 2015;31(8):547-55.

24. Sosnowski K, Lin F, Mitchell ML, et al. Early rehabilitation in the intensive care unit: An integrative literature review. Aust Crit Care. $2015 ; 28(4): 216-25$. 
25. Tipping CJ, Harrold M, Holland A, et al. The effects of active mobilisation and rehabilitation in ICU on mortality and function: a systematic review. Intensive Care Med. 2017;43(2):171-83.

26. Li Z, Peng X, Zhu B, Zhang Y. et al. Active Mobilization for Mechanically Ventilated Patients: A Systematic Review. Arch Phys Med Rehabil. 2013;94(3):551-61.
27. Adler J, Malone D. Early mobilization in the intensive care unit: a systematic review. Cardiopulm Phys Ther. 2012;23(1):5-13.

28. Knaus W, Draper E, Wagner D, et al. (1985) APACHE II: A severity of disease classification system. Crit Care Med. 1985; 13(10):818-29. 